\title{
Comparison of unplanned intensive care unit readmission scores: a prospective cohort study
}

\author{
C Roehrig, RG Rosa*, AM Ascoli, L Madeira, W Rutzen, J Maccari, P Balzano, AC Antonio, P Castro, RPd Oliveira, \\ C Teixeira
}

From ESICM LIVES 2015

Berlin, Germany. 3-7 October 2015

\section{Introduction}

Early discharge from intensive care unit (ICU) may constitute a strategy of resource consumption optimization; however, unplanned readmission of hospitalized patients to an ICU is associated with a worse outcome.

\section{Objectives}

To compare the effectiveness of the stability and workload index for transfer score (SWIFT), the sequential organ failure assessment score (SOFA) and simplified therapeutic intervention scoring system (TISS-28) in predicting unplanned ICU readmission or unexpected death in the first 48 hours after discharge from the ICU.

\section{Methods}

We conducted a prospective cohort study in a single tertiary hospital in Southern Brazil. All adult patients admitted to the ICU for more than 24 hours from January 2008 to December 2009 were evaluated. SWIFT, SOFA and TISS-28 scores were calculated on the day of discharge from ICU. A stepwise logistic regression was conducted for evaluation of the effectiveness of these scores in predicting unplanned ICU readmission or unexpected death in the first 48 hours after discharge from the ICU. Moreover, we conducted a direct accuracy comparison among SWIFT, SOFA and TISS-28 scores.

\section{Results}

In total 1277 patients were discharged from the ICU during the study period. The rate of unplanned ICU readmission or unexpected death in the first 48 hours after discharge from the ICU was $15 \%$ (192 patients). In the multivariate analysis,age $(P=0.001)$, length of ICU stay $(P=0.01)$, cirrhosis $(P=0.03)$, SWIFT $(P=0.001)$,

Moinhos de Vento Hospital, Porto Alegre, Brazil
SOFA $(P=0.01)$ and TISS-28 $(P<0.001)$ constituted predictors of unplanned ICU readmission or unexpected death. SWIFT, SOFA and TISS-28 scores showed similar predictive accuracy (AUC 0.65, 0.65 and 0.67 , respectively, $P=0.58$ ).

\section{Conclusions}

SWIFT, SOFA and TISS-28 on the day of discharge from ICU may constitute important tools to predict ICU readmission or death. The present study did not find any accuracy difference among the three scores.

Published: 1 October 2015

\section{Reference}

1. Gajic O, Malinchoc M, Comfere TB, Harris MR, Achouiti A, Yilmaz M, et al: The Stability and Workload Index for Transfer score predicts unplanned intensive care unit patient readmission: Initial development and validation. Crit Care Med 2008, 36(3):676-682.

doi:10.1186/2197-425X-3-S1-A472

Cite this article as: Roehrig et al:: Comparison of unplanned intensive care unit readmission scores: a prospective cohort study. Intensive Care Medicine Experimental 2015 3(Suppl 1):A472.

Submit your manuscript to a SpringerOpen ${ }^{\bullet}$ journal and benefit from:

- Convenient online submission

- Rigorous peer review

- Immediate publication on acceptance

- Open access: articles freely available online

- High visibility within the field

Retaining the copyright to your article

Submit your next manuscript at $>$ springeropen.com (c) 2015 Rosa et al.; This is an Open Access article distributed under the terms of the Creative Commons Attribution License (http:// creativecommons.org/licenses/by/4.0), which permits unrestricted use, distribution, and reproduction in any medium, provided the original work is properly cited. 